\title{
A New Mathematical Model For Assessment of Memorization Dynamics
}

\author{
Igor I. Stepanov ${ }^{1}$ and Charles I. Abramson ${ }^{2}$ \\ ${ }^{1}$ Institute for Experimental Medicine, St. Petersburg, Russia. \\ ${ }^{2}$ Oklahoma State University, USA
}

\begin{abstract}
A new memory model is proposed based on regression analysis and exponential- shaped learning curves. The efficacy of the model is tested with several types of experiments including food aversion in snails, maze learning in rats and memory tests for adults and children. The model is also tested on drug abusers and alcoholics. The results of goodness of fit tests indicate that our model can accurately be used to predict the memory dynamics of diverse experiments and populations. The model can also be used to predict both group and individual performance. The application of the model to detect memory impairment is discussed, as are limitations.
\end{abstract}

Keywords: learning, memory, memorization dynamics, learning dynamics

\begin{abstract}
Se propone un nuevo modelo de memoria basado en el análisis de regresión y las curvas exponenciales de aprendizaje. La eficacia del modelo se verifica con varios tipos de experimentos incluyendo la aversión a la comida en caracoles, el aprendizaje de laberintos en ratas y las pruebas de memoria en adultos y niños. El modelo también se pone a prueba en drogadictos y alcohólicos. Los resultados de las pruebas de bondad de ajuste indican que nuestro modelo puede ser empleado con precisión para predecir las dinámicas de la memoria en diversos experimentos y poblaciones. También puede emplearse el modelo para predecir tanto la ejecución grupal como la individual. Se comenta la aplicación del modelo para detectar el deterioro de la memoria, así como las limitaciones del mismo. Palabras clave: aprendizaje, memoria, dinámica de la memoria, dinámica del aprendizaje
\end{abstract}

The authors wish to thank their colleagues taking part in some aspects of this work. The psychophysiologists - Dr. Nikolay Maidanov, M.D., Dr. Sergey Schklyaruk, M.D., Ph.D; the database programmer - Mikle Danilovsky, bachelor of technical science; the WEB and computer graphic designer — Dr. Arina Dzeniskevitch; the artist — Dr. Ludmila Ivanova; the beta tester — Dr. Oleg Efremov, M.D., Ph.D.

Correspondence concerning this article should be addressed to Igor I. Stepanov, Department of Neuropharmacology, Institute for Experimental Medicine, 12 Acad. Pavlov Street, St. Petersburg, 197376, Russia. E-mail: igorstep@is12044.spb.edu 
The purpose of this paper is to suggest a new test to detect the early onset of memory dysfunction such as that associated with Alzheimer's disease, diabetes, and some endocrinological diseases. This test was first developed to account for the performance of invertebrates in various learning paradigms such as habituation and classical conditioning and now has been extended to a wide range of training situations with various organisms including humans.

Changes in working memory are generally the earliest cognitive indicator seen in Alzheimer's disease (Albert, 1996). The successful characterization of the decline in memory during normal aging would assist in distinguishing the pathological memory change indicative of Alzheimer's disease as distinct from age-related normal changes.

Current memory tests, such as the California Verbal Learning Test (Delis, Kramer, Kaplan, \& Ober, 1987), the "Mini-Mental State" (Folstein, Folstein, \& McHugh, 1975), the Selective Reminding Test (Grober \& Buschke, 1987), the Wechsler Memory Scale (Wechsler, 1987), and the Cambridge Neuropsychological Test Automated Battery (Robbins et al., 1994; Swainson et al., 2001) calculate only the number of correct answers but do not pay attention to the dynamics of memory formation as the integral process. Moreover, we believe that a simple pre- and posttest comparison of, for example, savings scores cannot detect fine differences in learning dynamics. It is the detection of such moment by moment changes in performance that can be used in the diagnosis and treatment of Alzheimer's and other diseases that affect memory impairment.

The laboratory of the senior author has been researching the dynamics of learning and memory in humans and animals since 1980. This research has produced a novel mathematical model that can be used to predict memory loss. Unfortunately, most of this work is published in Russian scientific journals and is not available for Western scientists. An additional purpose of the paper is to show the development of the model and illustrate the basic results. Though this paper is predominantly a review, we included a method section for a better understanding of results and approaches.

\section{Methods}

\section{Elaboration of Food Aversion in the Land Snail, Helix Pomatia}

The basic procedure has been previously described (Stepanov \& Lokhov, 1986). A food-deprived snail is restrained on a plastic ball. When the animal seized a small piece of carrot or cabbage an electric shock was presented. A session consisted of 10 trials per day and there were a total of 5 consecutive sessions. After a number of seizing food-shock pairings, the hungry snail no longer contacts the food.

\section{Light-Dark Discrimination in Rats with Positive Food Reinforcement in a Y-Maze}

In this experiment, adult male Wistar rats were tested in a standard Y maze (Sapronov \& Stepanov, 2004). Prior to training, animals explored the maze for one week. After the adaptation period, training began and consisted of rewarding the animal in the lighted arm of the maze with a small piece of cheese. In order to obtain reward, the rat must run into the non-preferred arm. A session consisted of 20 trials per day and there were a total of 5 consecutive sessions.

\section{Surgery for Injection of Beta-Amyloid in Rats}

One of the aims of the light-dark discrimination experiment described above was to study the influence of beta-amyloid on learning (Maurice, Lockhart, \& Privat, 1996). Beta-amyloid was injected into the IV ventricle in accordance with the brain atlas of Paxinos and Watson (1986). Control animals were injected with sterile distilled water. Y-maze light/dark discrimination learning began 15 days post injection.

\section{Conditioned Eye Blink Reflex in Humans}

Ten adult volunteers of both genders were subjected to a conditioned eye blink task (Lokhov, Stepanov, \& Vartanian, 1990). The conditioned stimulus (CS) was $300 \mathrm{~Hz}$ tone with duration of 5 seconds and the unconditioned stimulus (US) was a puff of air to the eye. Interval between the onset of the sound and a puff of air was $3 \mathrm{~s}$. Each participant received 20 CS-US pairings per day for a total of 100 trials. Possible reaction on the conditioned stimulus was extinguished during 3-4 trial with isolated action of sound prior to conditioning. Blinking was registered by sight.

\section{Memorization of 10 Words}

Sixteen healthy volunteers of both genders (age 25-35 years old) were compared to 20 male drug addicts (age 1952) and 80 male alcoholics (age 24-60) in their ability to memorize a list of nouns. The nouns were selected from the "Russian language frequency vocabulary" with a frequency of not more than 12\% (Lokhov \& Stepanov, 1988). The experimental protocol was similar to that used for the California Verbal Learning Test (Delis et al., 1987) with the exception that 10 nouns were used and the test consisted of 10 trials. The number of correct responses, excluding repetitions, served as the dependent variable.

\section{Memorization of 12 Two-Digit Numbers}

Ten adult volunteers of both genders (age 25-35) were required to memorize 12 numbers. The numbers were obtained from a random numbers table. Each subject received 10 training trials. The number of correct responses, excluding repetitions, was the dependent variable (Lokhov \& Stepanov, 1988). 


\section{Memorization of Pairs of Visual Images in Children}

This experiment was performed with children varying in age. One group consisted of 15 children (age 3.2-4.5), a second of 14 children (age 4.6-5.4), and a third of 15 children (age 5.7-6.3). In addition, a sample of 30 children (age 6-7) who suffered from stuttering was also examined. This memory test was designed specially for children of preschool age (Lokhov \& Stepanov, 1987). Six pairs of images with similar semantic meaning and 6 pairs of images with different semantic meaning were designed. Every pair was shown for $5 \mathrm{~s}$ with a 5 -s interpresentation interval. The basic design required a child to recall the second member of the pair following presentation of the first member of the pair. The dependent variable was the number of correct responses. The experiment consisted of two sessions. In the first session, the children were exposed to images with similar semantic meanings and in the second session, to images with different semantic meanings.

\section{Mathematical Model for Learning and Memorization Dynamics}

Learning and memorization is regarded as the reaction of the first order linear system in response to stepwise input action (Stepanov, 1983). Our mathematical model is the transfer function of this reaction: $\mathrm{Y}=\mathrm{B} 3^{*} \exp (-\mathrm{B} 2 * \mathrm{X})+$ $\mathrm{B} 4 *(1-\exp [-\mathrm{B} 2 * \mathrm{X}])$. The advantage of the model lies in estimating three parameters: B2-the velocity of memorization (learning); B4-an asymptotic volume of memorized (learned) objects; B3-predisposition to the next memorization (learning) before the beginning of testing, (i.e., at $X=0$ ). From a psychological point of view, coefficient B3 represents pretrial associative strength, and coefficient B4-behavioral saturation level for associative strength.

Assessment of pretrial associative strength or, in other words, predisposition to the next memorization (learning) of new information, is very important. Many mathematical models of learning and memorization (including the frequently used Weibull function) do not allow estimating the value of correct responses prior to next learning trial, as $\mathrm{Y}=0$ at $\mathrm{X}=0$ (Gallistel, Fairhurst, \& Balsam, 2004; Gulliksen, 1934; Hull, 1943).

Other memory models based on the theory of probabilities, also suppose that $\mathrm{Y}=0$ at $\mathrm{X}=0$, because of the way the term "probability" is defined $\mathbf{P} \in[0,1]$ (Atkinson, Bower, \& Crothers, 1965). Still another approach relies on automatic control theory, which studies transfer functions of any system on different input actions. In particular, the transfer function of the first order system in response to stepwise external stimulus looks like:

$$
\mathrm{y}=\left(\mathrm{y}_{0}-\mathrm{y}_{\mathrm{ss}}\right) \exp (-\mathrm{t} / \tau)+\mathrm{y}_{\mathrm{ss}},
$$

where $\tau=$ the time constant of the system, $\mathrm{y}_{0}=$ initial system state at $\mathrm{X}=0, \mathrm{y}_{\mathrm{ss}}=$ asymptotic steady state at $\mathrm{X}$ equal to infinity (Grodins, 1963). What is important for the application to memorization is that the initial and final system states be arbitrary, so $y_{0}$ is allowed not to be equal to zero at all experimental situations. Based on this theory, Towill showed that learning of some work skills was fitted well with a transfer function of the first order system (Towill, 1976).

\section{Regression Analysis of Memorization Dynamics}

The mathematical model we proposed is in the class of intrinsically nonlinear models. This means that it is impossible to derive suitable formula for calculating the coefficients of the model, as is common for any linear regression model (Draper \& Smith, 1981; Himmelblau, 1970). Most modern statistical packages (e.g., SPSS or SAS) use iterative estimation algorithms (using input of start values) such as sequential quadratic programming or Levenberg-Marquardt for estimating the coefficients for a nonlinear regression model and asymptotic standard errors of coefficients, but only rough values can be obtained. If these starting values are very far from the final values, then error estimation can be rather large.

Stepanov (1983) derived all mathematical equations for direct search of the coefficients B2, B3, and B4 and calculation of their variances as well as for comparison of the same coefficients. Verification of the model and its compliance with experimental data was performed with the test for goodness of fit both for linear models (Himmelblau, 1970) and with approximate test for goodness of fit for nonlinear models (Draper \& Smith, 1981). Strictly speaking, it is possible to receive only rough estimates of variance of measurement error for nonlinear regression models, so we assume that the mathematical model complies rather well with experimental data, if appropriate terms were fulfilled for both tests for goodness of fit for linear and nonlinear models.

If the regression analysis is applied not to a group of persons, but to a single subject, then measurement error variance can not be estimated separately from residual variance. The residual variance is an estimation of the quality of the fit. The less the residual variance, the closer the experimental and model values are situated. In other words, in the case of fitting a single learning or memorization test, it is impossible to estimate quantitatively the quality of fit with the mathematical model. One way to estimate the strength of the correlation is to calculate so-called $R^{2}$, that is the square of the correlation relation.

$$
\mathrm{R}^{2}=1-\frac{\sum_{i=1}^{\mathrm{n}}\left(\mathrm{Y}_{\mathrm{i}}-\hat{\mathrm{Y}}_{\mathrm{i}}\right)^{2}}{\sum_{i=1}^{\mathrm{n}}\left(\mathrm{Y}_{\mathrm{i}}-\overline{\mathrm{Y}}\right)^{2}},
$$

where $\mathrm{n}=$ the number of trials, $\mathrm{Y}_{\mathrm{i}}=$ the experimental value, $\hat{Y}_{i}=$ calculated model value, $\bar{Y}=$ the average mean calculated over all experimental values. It is used in Excel, SPSS, and other statistical packages. Unfortunately, it is not 
possible to calculate significance with these statistics (Kendall $\&$ Stuart, 1975). Nevertheless, $R^{2}$ is useful for a quantitative estimate of the fit.

Additionally, we restricted the value of the coefficient B2. Coefficient B2 must exceed zero by definition of the mathematical model. The upper limit we established for B2 is 3.0. In other words, we suppose that the exponential curve really exists, if $0.005<\mathrm{B} 2<3.0$. This limitation gives satisfactory results in practice.

\section{Results}

\section{Learning Dynamics in Land Snails}

Learning of food aversion in the land snail, Helix pomatia, corresponded well to our model based on goodness-of-fit tests (Stepanov \& Lokhov, 1986). It was found that the dynamics was different for a preferred food-carrot and a non-preferred food-cabbage. If cabbage was used, the coefficient B3 value was close to zero (Figure 1.A). If carrot was chosen, the coefficient B3 value was negative (Figure 1.B).
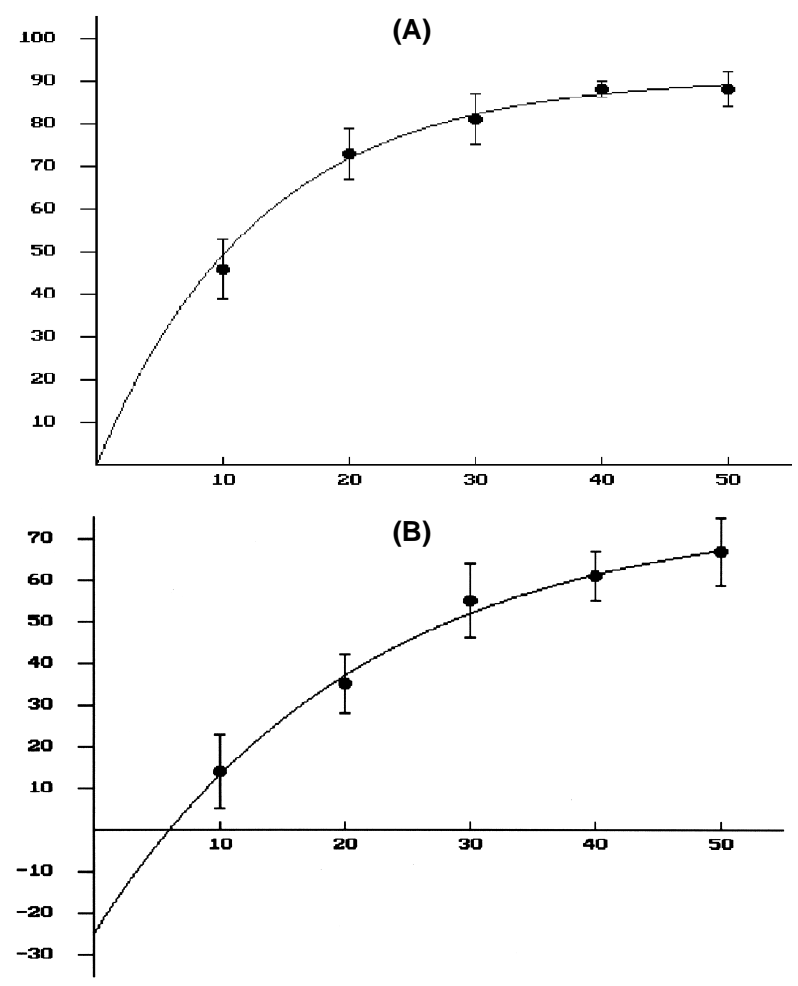

Figure 1. The dynamics of food avoidance learning in the land snail Helix pomatia.

$A-$ stimulus is cabbage ( 29 snails) $\mathrm{B} 2=0.078 \pm 0.003$; $\mathrm{B} 3=0 \pm 3$; B4 $=91 \pm 3$.

$B-$ stimulus is carrot ( 8 snails) $\mathrm{B} 2=0.047 \pm 0.003$; B $3=-25 \pm 7$; B4 $=77 \pm 4$. Filled dots with vertical lines are means with S.E.M. Solid curve is fitting with the mathematical model. Abscissa $=$ total number of trials; ordinate $=$ percentage of conditioned responses (food refusals).
It is important to pay attention to coefficient B3. Negative values of B3 can be interpreted as the result of any preexisting inhibitory influence on the next learning trial. On the other hand, positive values of coefficient B3 point to any facilitatory preexisting influence on learning. The possibility of quantitative assessment of learning dynamics and comparison of the values of coefficients is of great value to the model. This feature allowed us to study facilitatory and inhibitory influence of blood sampled from trained recipients onto conditioning of untrained donor snails (Balaban \& Stepanov, 1996; Stepanov, Lokhov, Satarov, Kuntsevich, \& Vartanyan, 1988).

\section{Learning Dynamics during Light-Dark Discrimination in Wistar Rats}

Light-dark discrimination in a Y-maze with positive food reinforcement, assessed as a decrease in the number of errors, was significantly fitted with our model (Figure 2.A). Both tests for goodness of fit showed that the model fitted the data well. Injection of beta-amyloid into the IV ventricle of the brain led to a disruption in performance between the first and the second session without total cessation of the learning process (Figure 2.B). This disappearance of the curve may be the first sign of the initial effect of beta-amyloid and, probably, preclinical symptom for future Alzheimer's (Sapronov \& Stepanov, 2004).
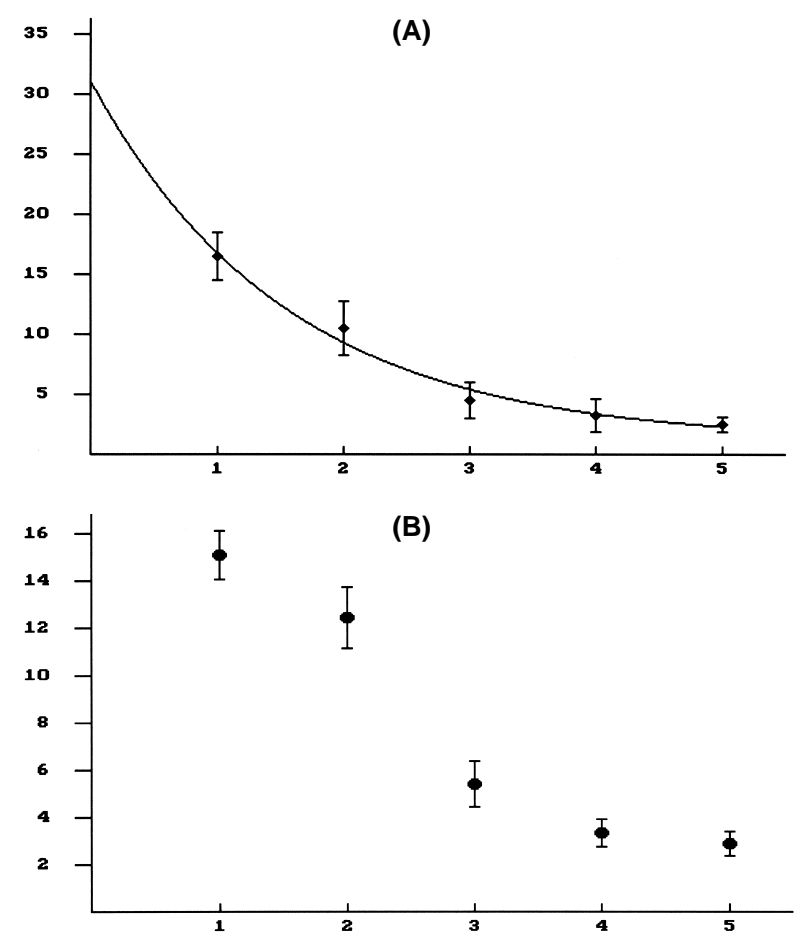

Figure 2. The dynamics of learning during light-dark discrimination in the Y-maze.

$A$ - The learning dynamics for the Wistar control group (8 rats). $\mathrm{B} 2=0.65 \pm 0.027 ; \mathrm{B} 3=31.0 \pm 3.4 ; \mathrm{B} 4=1.2 \pm 0.83$. $\mathrm{B}$.

$B$ - The learning dynamics for the Wistar amyloid-treated group (9 rats). Filled dots with vertical lines are means with S.E.M. Abscissa $=$ the number of errors; ordinate $=$ session number . 


\section{Eye Blink Conditioned Reflex in Humans}

The same mathematical model was successfully used for fitting of eye blink conditioned reflex in humans. Both tests for goodness of fit showed that the mathematical model fitted the data significantly. The square of correlative relation $R^{2}$ $=.995$. Testing values practically coincided with mathematical model ones (Figure 3). The negative value of coefficient B3 can be explained due to the addition of an extinction session. We would like to note that our model fits the simple paradigms of learning behavior of snails, rats, and humans and supports the suggestion that the fundamental mechanisms of learning are very similar in very different organisms.

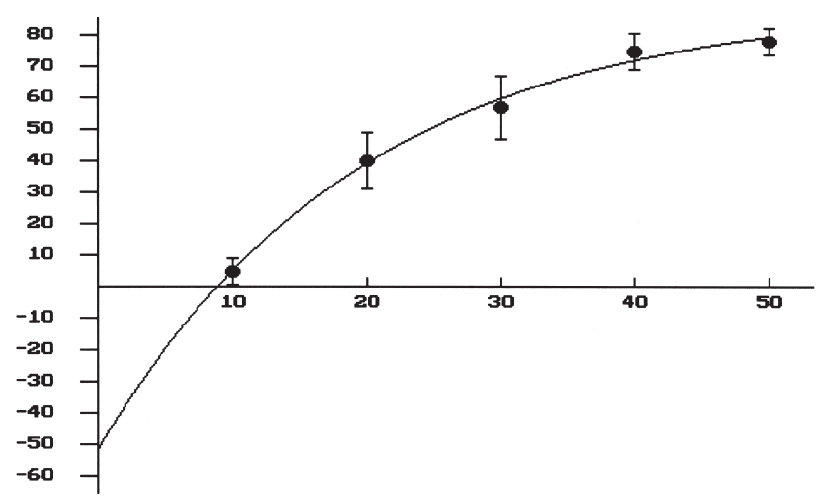

Figure 3. Dynamics of elaboration of conditioned eye blinking reflex in man.

B2 $=0.048 \pm 0.003 ; \mathrm{B} 3=-52 \pm 4 ; \mathrm{B} 4=92 \pm 5$. Filled dots with vertical lines are means with S.E.M. Solid curve is fitting with the mathematical model. Abscissa = total number of trials; ordinate $=$ percentage of conditioned responses.

\section{Memorization Dynamics Curve Averaged for a Group of People}

A test for memorization of words is frequently used in applied psychological, neurological, and psychiatrical examinations. In Russia, it was developed by the well-known psychologist, A. Luria (1962). Luria's test is very close to the California Verbal Learning Test's memorization words from List A (Delis et al., 1987). That is why we wondered if our mathematical model could be used for this test. Our experiments on healthy volunteers revealed that both tests for goodness of fit showed that the mathematical model fitted well the process of word memorization (Lokhov \& Stepanov, 1988). The square of correlative relation was $R^{2}$ $=.98$. It is interesting to mention that the list consisted of well-known words, so the coefficient B3 took the value of $32.5 \%$, and subjects could memorize practically all the words to the end of the test (Figure 4.A). Thus, the value of B3 can be the objective estimation for the level of familiarity of the subject under testing with the words under memorization. We believe that dynamics of memorization of words from list A in the California Verbal Learning Test will provide a good fit with our mathematical model. In this case our mathematical model could become a very useful tool for increasing the self-descriptiveness and value of the California Verbal Learning Test.

Memorization of numbers is the other more or less widely used memory test, so we applied our mathematical model for this test also with adult volunteers of both genders. Experiments showed that the mathematical model fitted well the process of two-digit numbers memorization (Lokhov \& Stepanov, 1988). Testing values practically coincide with math model ones. The square of correlative relation was $R^{2}=.98$. The numbers happened to be more difficult for memorization, as can be judged from the coefficient B3, which took value of $12 \%$, as shown in Figure 4.B. Use of both tests simultaneously can give more information than any one. For example, our pilot experiments showed that $30 \mathrm{~min}$ after drinking $50 \mathrm{ml}$ of $40 \%$ alcohol (Russian vodka), memorization of words was facilitated, but memorization of numbers was not fitted significantly with the mathematical model.
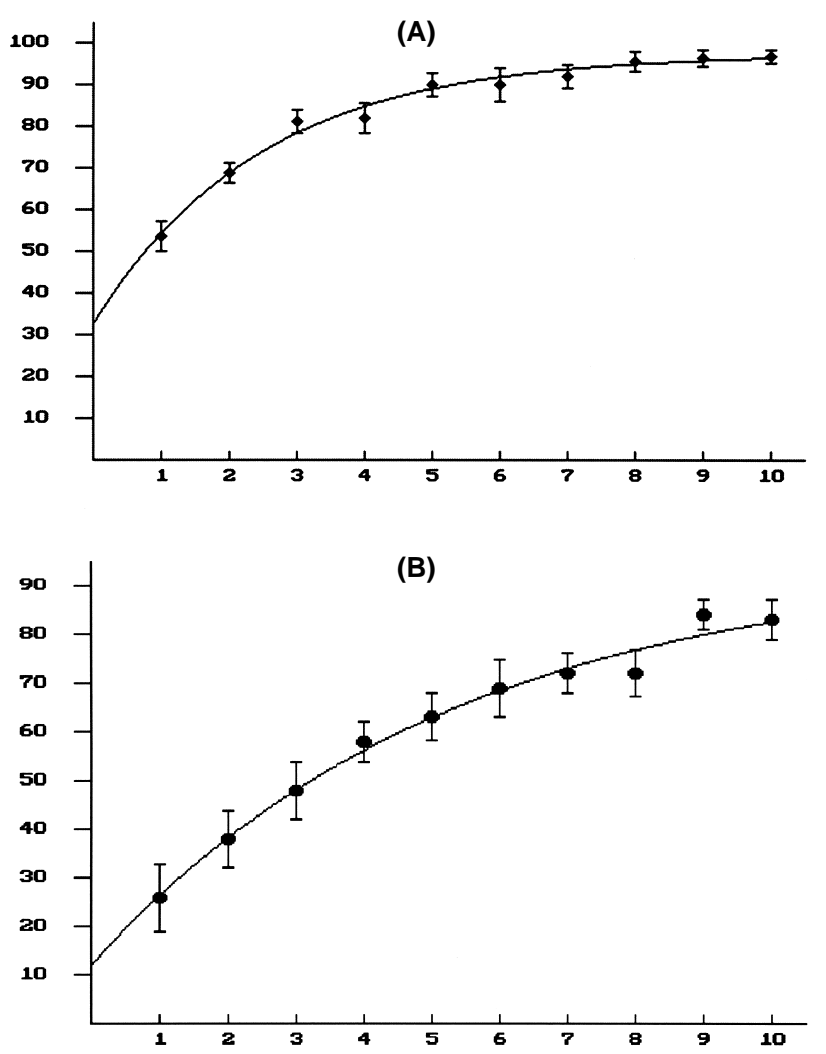

Figure 4. Dynamics of memorization of words and numbers in adults. $A$ - Memorization of 10 Russian words under verbal presentation; $\mathrm{B} 2=0.41 \pm 0.01 ; \mathrm{B} 3=32.5 \pm 3.6 ; \mathrm{B} 4=97.4 \pm 1.1$.

$B$ - Memorization of 12 two-figure numbers under visual presentation; $\mathrm{B} 2=0.19 \pm 0.04 ; \mathrm{B} 3=12 \pm 1.7$; B4 $=95 \pm 1.3$. Filled dots with vertical lines are means with S.E.M. Solid curve is fitting with the mathematical model. Abscissa = the number of the set of words or numbers presentation (trial); ordinate $=$ percentage of correct responses. 
Being encouraged with our success in modeling a memorization test of 10 words on normal subjects, we attempted to model patients with neurological and psychiatric disorders. We found that treatment of patients suffering from drug addiction and alcoholism led to improvement of test performance (Shabanov, Stepanov, Usenko, \& Goncharov, 2000). Both tests for goodness of fit showed that the mathematical model provided an excellent fit to the experimental data. The results of a comparison of the model coefficients are given in Table 1.

In patients suffering from drug addiction, the coefficient B3 is lower in comparison with alcoholics. Treatment with auricular acupuncture led to a pronounced improvement in performance in our memory test, all the three coefficients being significantly improved. It is notable that coefficient B3 increased more than 5 times following acupuncture treatment (Figure 5.A). In alcoholics, the treatment improved memorization due to a significant elevation of the asymptotic level. At the same time, the initial level-coefficient B3did not change (Figure 5.B). This example shows that our mathematical model can provide qualitative information to allow a clinician to asses the effects of acupuncture treatment on drug addicts and alcoholics.

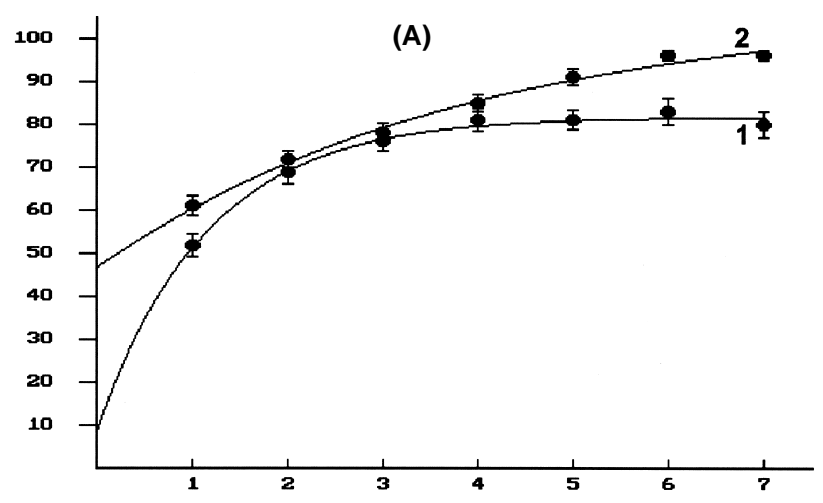

We also used the test for memorization of 10 words together with our regression analysis to assess the use of Piracetam, Nootropil, Baklophen, and Bemethyl to treat alcoholics as shown in Figure 6 and in Table 2 (Sapronov \& Stepanov, 1996; Goncharov, Usenko, \& Stepanov, 2002). All patients were men between the ages of 24-60. Our model was used to estimate the activity of drugs in more detail. Piracetam with vitamins improved memorization via an increase of pretrial associative strength (coefficient B3) and significant increased velocity (coefficient B2; Figure 6.A). Treatment with Nootropil led to a 3.5 times increase in velocity of memorization (coefficient B3) over pretreatment levels (Figure 6.B). Baklophen improved memorization in similar way as piracetam with vitamins, though less pronounced (Figure 6.C). Bemethyl was found not to provide a good fit with our model (Figure 6.D). The lack of a fit suggests that it is not desirable to use bemethyl because of its disruption of memory (i.e., the curve did not correspond to the predicted shape). The application of our model to neurotropic drugs suggests the model can be used to evaluate and compare the efficacy of new treatment strategies and to identify drugs that may be inappropriate because of their effect on memory formation.

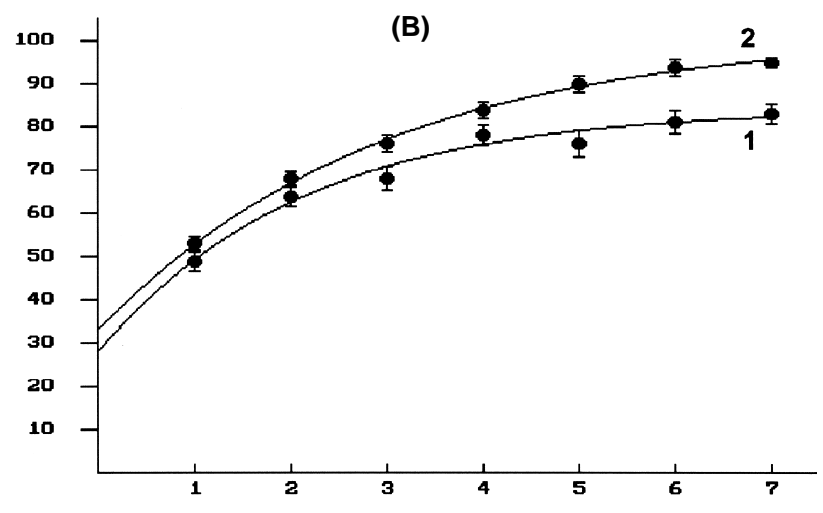

Figure 5. Regression analysis of memorization of 10 words in patients.

$A$ - patients suffering from drug addiction; $B$ - patients suffering from alcoholism.

1 - before treatment; 2 - after treatment with auricular acupuncture. Filled dots with vertical lines are means with S.E.M. Solid curve

is fitting with the mathematical model. Abscissa $=$ the number of test representation; ordinate $=$ percentage of correct responses.

Table 1

Regression Analysis of Memorization of 10 Words in Patients Suffering from Drug Addiction and Alcoholism

\begin{tabular}{|c|c|c|c|c|c|}
\hline \multicolumn{3}{|c|}{ Patients suffering from drug addiction } & \multicolumn{3}{|c|}{ Patients suffering from alcoholism } \\
\hline B2 & B3 & B4 & B2 & B3 & B4 \\
\hline \multicolumn{6}{|c|}{ Before treatment } \\
\hline $0.88 \pm 0.06$ & $8.6 \pm 12.3$ & $81.8 \pm 2.3$ & $0.48 \pm 0.04$ & $27.8 \pm 6.1$ & $84.3 \pm 2.5$ \\
\hline$p<.0001$ & $p<.0001$ & $p<.0001$ & $p<.0001$ & $p=.14$ & $p<.0001$ \\
\hline \multicolumn{6}{|c|}{ After treatment with auricular acupuncture } \\
\hline $0.26 \pm 0.01$ & $46.7 \pm 3.7$ & $106.9 \pm 2.0$ & $0.34 \pm 0.01$ & $33.0 \pm 3.4$ & $102.1 \pm 1.8$ \\
\hline
\end{tabular}


Table 2

Regression Analysis of Alcoholics Treated with Some Neurotropic Drugs

\begin{tabular}{|c|c|c|c|c|c|}
\hline \multicolumn{3}{|c|}{ A - piracetam with vitamins } & \multicolumn{3}{|c|}{ B - nootropil } \\
\hline $\mathrm{B} 2$ & B3 & B4 & B2 & B3 & B4 \\
\hline \multicolumn{3}{|c|}{ Before treatment } & \multicolumn{3}{|c|}{ Before treatment } \\
\hline $0.40 \pm 0.02$ & $17.5 \pm 5.7$ & $96.3 \pm 2.2$ & $0.07 \pm 0.002$ & $38.1 \pm 1.6$ & $183.9 \pm 3.9$ \\
\hline$p<.005$ & $p<.01$ & $p>.2$ & $p<.0001$ & $p=.17$ & $p<.0001$ \\
\hline \multicolumn{3}{|c|}{ After treatment } & \multicolumn{3}{|c|}{ After treatment } \\
\hline $0.44 \pm 0.02$ & $31.9 \pm 5.6$ & $97.2 \pm 2.0$ & $0.25 \pm 0.008$ & $35.5 \pm 3.5$ & $111.1 \pm 1.9$ \\
\hline \multicolumn{3}{|c|}{$\mathrm{C}$ - baklophen } & \multicolumn{3}{|c|}{ D — bemethyl } \\
\hline $\mathrm{B} 2$ & B3 & B4 & $\mathrm{B} 2$ & B3 & B4 \\
\hline \multicolumn{3}{|c|}{ Before treatment } & \multicolumn{3}{|c|}{ Before treatment } \\
\hline $0.23 \pm 0.008$ & $34.9 \pm 2.5$ & $106.0 \pm 1.9$ & $0.1 \pm 0.004$ & $40.3 \pm 2.0$ & $141.7 \pm 3.6$ \\
\hline \multirow[t]{2}{*}{$p<.005$} & $p<.001$ & $p>.2$ & & & \\
\hline & ter treatme & & \multicolumn{3}{|c|}{ After treatment } \\
\hline $0.25 \pm 0.01$ & $41.8 \pm 2.8$ & $106.8 \pm 1.8$ & \multicolumn{3}{|c|}{ Not fitted with the mathematical model } \\
\hline
\end{tabular}
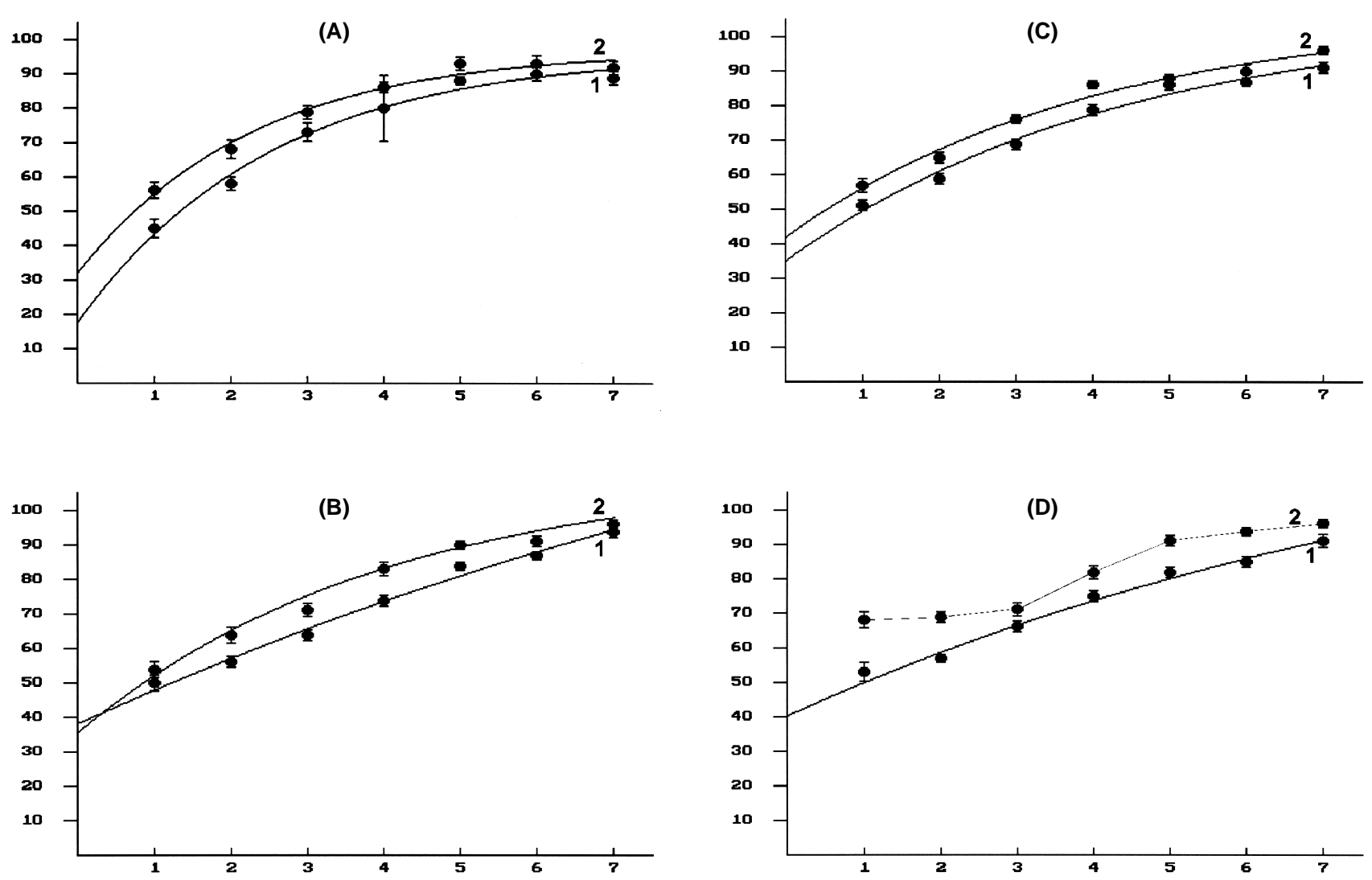

Figure 6. Regression analysis of alcoholics treated with some neurotropic drugs. $A$ - piracetam with vitamins; $B$ - nootropil; $C$ - baklophen; $D$ - bemethyl.

1 - before treatment; 2 - after treatment (fitting is absent in $D$ ). Filled dots with vertical lines are means with S.E.M. Solid curve is fitting with the mathematical model. Abscissa $=$ the number of test representation; ordinate $=$ percentage of correct responses. 
Our mathematical model was also found to be useful for memory assessment in children (Lokhov, Stepanov, Edlina, \& Vartanian, 1993). We could differentiate performance associated with memorizing images with similar semantic meaning from images associated with different semantic meanings (Figure 7). We also noted that our model successfully detected age-related changes in performance (Figure 8). The curves for children 4.6 to 7 years old began with negative values (coefficient B3 was in the range from -3 to -23 ), with a similar velocity (coefficient B2 was in the range of 0.51 to 0.59). The memorization curve for children 3.2 to 4.5 years old had a positive value of the coefficient B3, but the velocity was three times slower (coefficient B2 $=0.17$ ). Moreover, the value of coefficient B4 (121\%) suggests that 6 training trials were not enough for this age group to reach asymptotic performance. Hence, the memorization curve for children 3.24.5 years old, on the whole, is situated below all other curves.

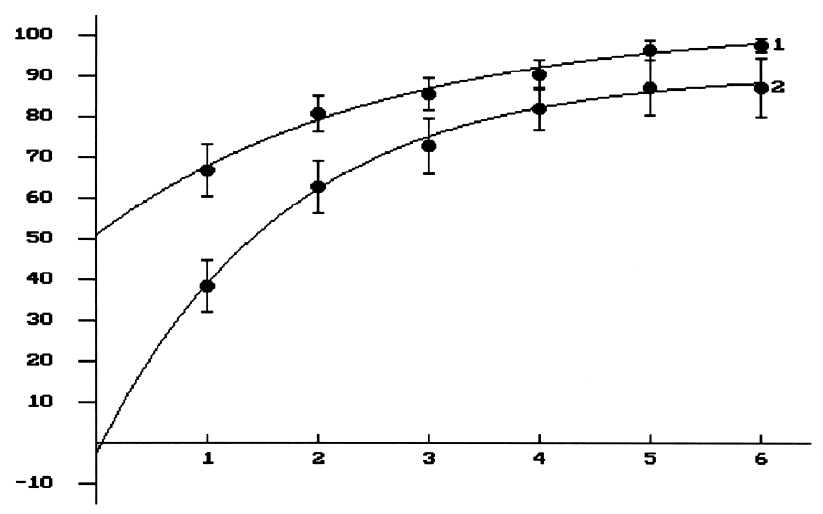

Figure 7. Memorization of pairs of visual images in healthy children in the age of 4.6-5.4 years old.

$1-$ similar objects, $\mathrm{B} 2=0.39 \pm 0.035, \mathrm{~B} 3=51+11.8, \mathrm{~B} 4=$ $103+3.7 ; 2-$ different objects, B2 $=0.59 \pm 0.073, \mathrm{~B} 3=-3 \pm 19.1$, B4 $=91 \pm 6.5$. Filled dots with vertical lines are means with S.E.M. Solid curve is fitting with the mathematical model. Abscissa $=$ the trial number; ordinate $=$ percentage of correct responses.

These experiments with healthy children laid the foundation for the development of an age-dependent scale for analyzing memory. Subsequent experiments with 6-7year old children who suffered from stuttering revealed that their memorization curve differed significantly from the curve of healthy children of the same age (Figure 9). In children suffering from stuttering, the velocity of memorization was 1.76 times less, and the curve began from a small positive value (coefficient B3 = 6.1). On the whole, dynamics of memorization in stutterers resembled the memorization curve of healthy 4-year-old children. From a clinical point of view, these results suggest that the complex treatment of speech impairment in stutterers must be completed with medicinal treatment aimed at activating the memory processes.

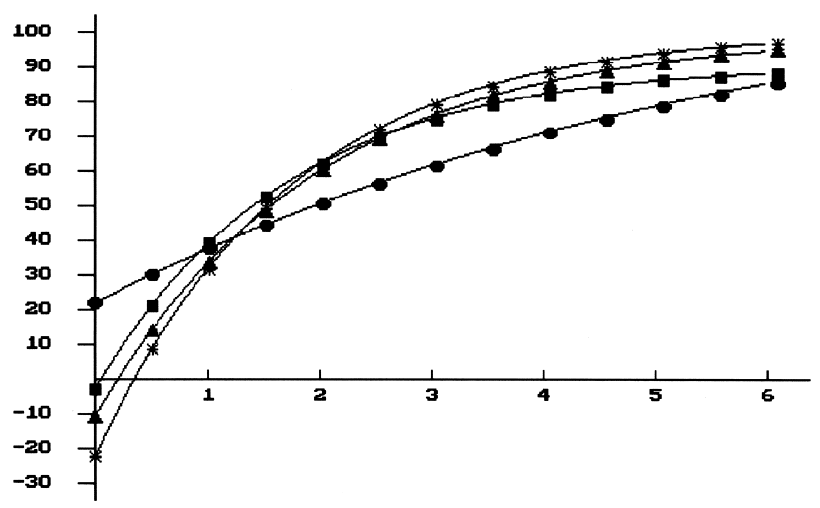

Figure 8. Memorization of pairs of visual images of different objects in healthy children.

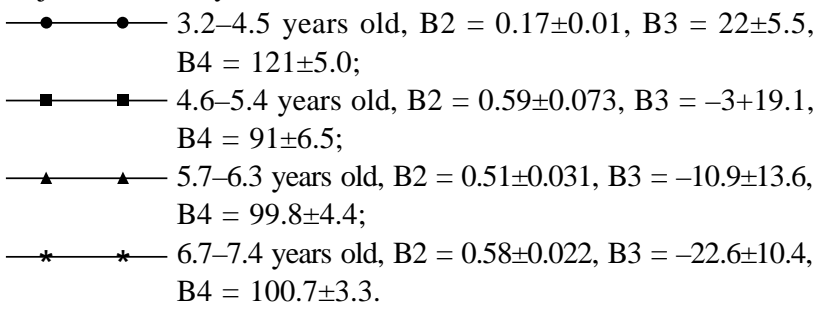

Solid curve is fitting with the mathematical model. Abscissa $=$ the trial number; ordinate $=$ percentage of correct responses .

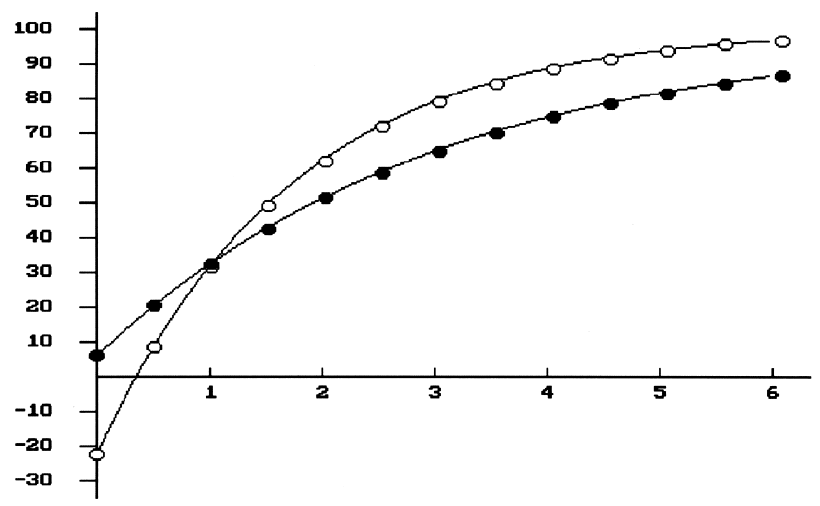

Figure 9. Memorization of pairs of visual images of different objects in healthy children and the stutterers.

Empty dots - healthy children $6-7$ years old, B2 $=0.58 \pm 0.022$, $\mathrm{B} 3=-22.6 \pm 10.4, \mathrm{~B} 4=100.7 \pm 3.3$; Filled dots - stutterers $6-7$ years old, B2 $=0.33 \pm 0.017, \mathrm{~B} 3=6.1 \pm 8.5, \mathrm{~B} 4=99.5 \pm 3.7$. Solid curves are constructed on the base of model values. Abscissa $=$ the number of the set of pictures presentation; ordinate = percentage of correct responses.

\section{Memorization Dynamics Curve for an Individual}

Averaging across subjects might give a misleading picture of what occurs in individual subjects (Gallistel et al., 2004; Wixted, 1997). To determine whether our model may provide such a misleading picture, we separately calculated individual memorization curves for each of 16 healthy volunteers who memorized 10 nouns under verbal presentation (Figure 4.A). The results are given in Table 3 . 
Table 3

Memorization of 10 Russian Words under Verbal Presentation for Every Subject from the Group of Healthy Men

\begin{tabular}{|c|c|c|c|c|c|c|}
\hline \multirow{2}{*}{ Subject } & \multicolumn{3}{|c|}{ Coefficients } & \multicolumn{2}{|c|}{ Correct answers, $\%$} & \multirow[t]{2}{*}{$R^{2}$} \\
\hline & $\mathrm{B} 2$ & B3 & B4 & Minimal case & Maximal case & \\
\hline 1 & $0.92 \pm 0.008$ & $-78.6 \pm 4.2$ & $100.9 \pm 0.6$ & 30 & 100 & .9951 \\
\hline 2 & $0.64 \pm 0.031$ & $-2.3 \pm 11.2$ & $100.4 \pm 2.4$ & 50 & 100 & .8913 \\
\hline 3 & $<0.0$ & - & - & 70 & 100 & - \\
\hline 4 & $1.17 \pm 0.008$ & $-125.1 \pm 4.9$ & $100.1 \pm 0.5$ & 30 & 100 & .9959 \\
\hline 5 & $0.61 \pm 0.009$ & $-11.2 \pm 3.6$ & $101.4 \pm 0.8$ & 40 & 100 & .9895 \\
\hline 6 & $0.29 \pm 0.008$ & $26.7 \pm 3.4$ & $107.8 \pm 1.6$ & 50 & 100 & .9693 \\
\hline 7 & $0.39 \pm 0.044$ & $53.5 \pm 8.7$ & $98.2 \pm 3.1$ & 70 & 100 & .6558 \\
\hline 8 & $<0.0$ & - & - & 60 & 80 & - \\
\hline 9 & $0.37 \pm 0.006$ & $56.6 \pm 9.0$ & $90.3 \pm 3.3$ & 70 & 100 & .492 \\
\hline 10 & $0.30 \pm 0.012$ & $23.2 \pm 4.8$ & $105.3 \pm 2.2$ & 40 & 100 & .9411 \\
\hline 11 & $0.34 \pm 0.022$ & $26.6 \pm 8.0$ & $104.6 \pm 3.3$ & 50 & 100 & .8564 \\
\hline 12 & $<0.0$ & - & - & 50 & 90 & - \\
\hline 13 & $<0.0$ & - & - & 70 & 100 & - \\
\hline 14 & $0.29 \pm 0.008$ & $26.7 \pm 3.4$ & $107.8 \pm 1.6$ & 50 & 100 & .9693 \\
\hline 15 & $<0.0$ & - & - & 70 & 100 & - \\
\hline 16 & $0.64 \pm 0.031$ & $-2.3 \pm 11.2$ & $100.4 \pm 2.4$ & 50 & 100 & .8913 \\
\hline
\end{tabular}

(A)

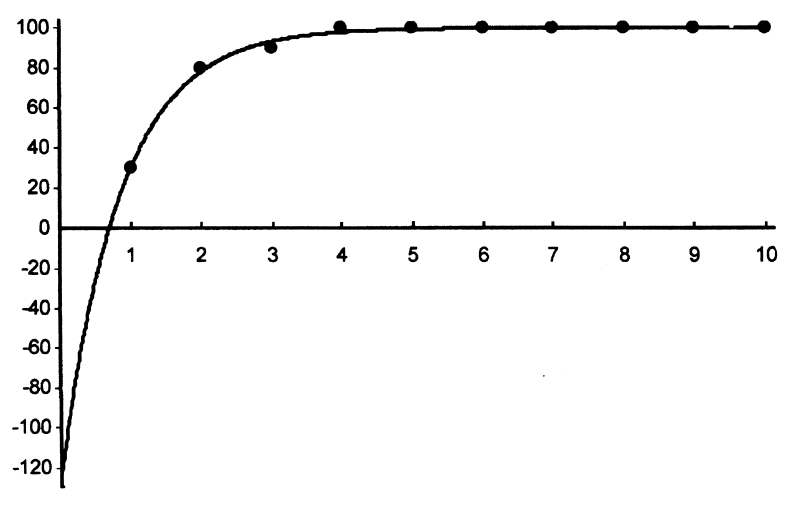

(B)

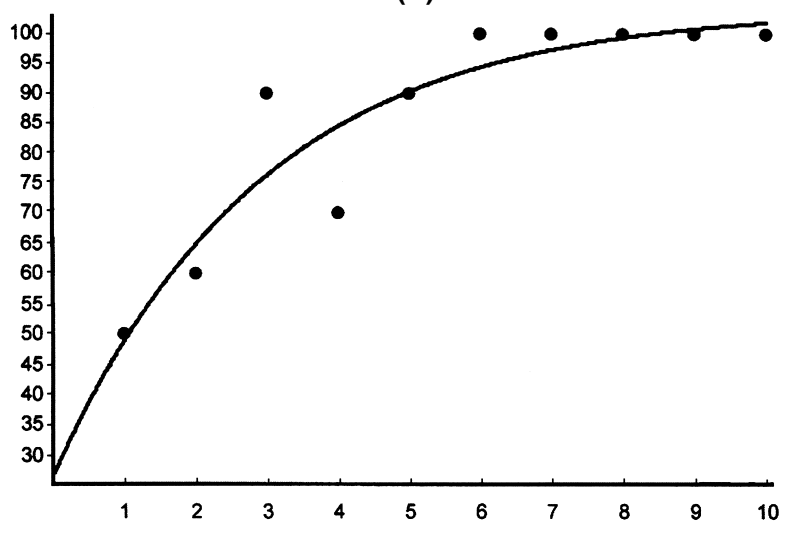

(C)

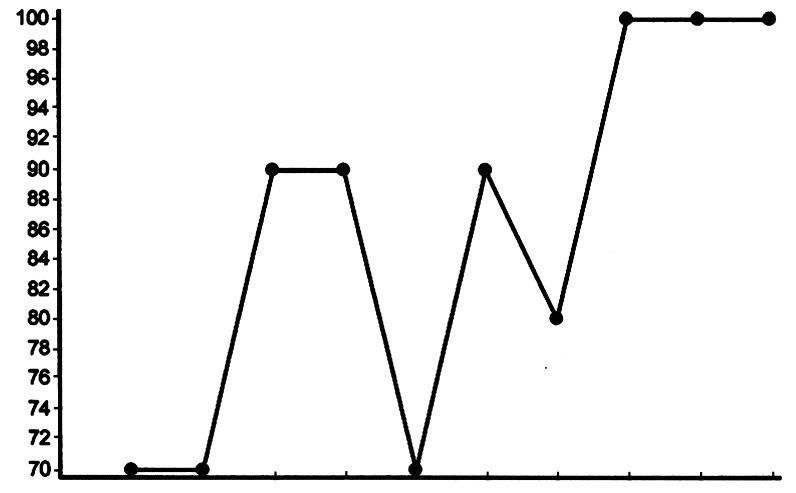

(D)

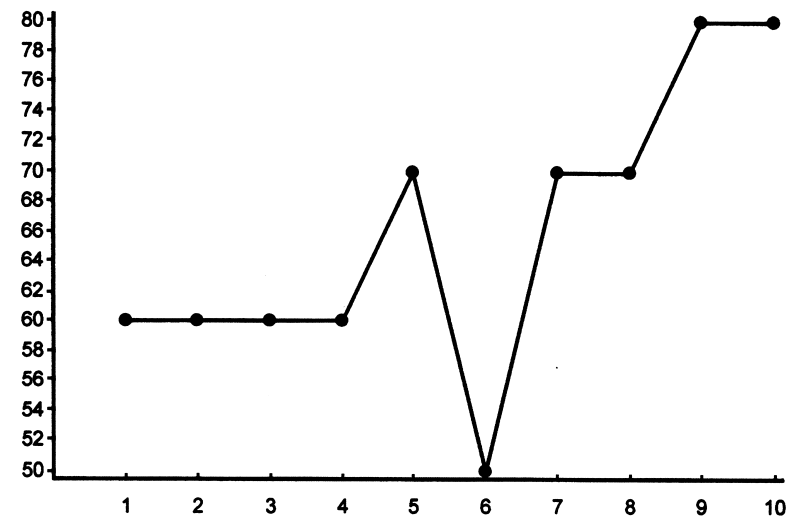

Figure 10. Individual memorization dynamics in healthy men for memorization of 10 Russian words.

$A-$ Subject 4 ; B2 $=1.17 ; \mathrm{B} 3=-125.1 ; \mathrm{B} 4=100.1 ; R^{2}=.9959 . B-$ Subject $11 ; \mathrm{B} 2=0.34 ; \mathrm{B} 3=26.6 ; \mathrm{B} 4=104.6 ; R^{2}=.8564 . C$ - Subject $13 ; D=$ Subject 8 . Black dots = experimental data; curves = result of calculations. Abscissa = the number of trial; ordinate $=$ percentage of correct responses. 
Memorization dynamics in 11 out of 16 subjects fitted our model well. The quality of the fit differed among individuals in these subjects, however. $R^{2}$ exceeded .8 in 9 out of these 11 subjects. Among the 5 subjects that did not show an exponential curve, it was found that the test values for three subjects ranged from $70 \%$ to $100 \%$. This indicates that the memory task may have been too easy for them. The remaining two subjects showed no exponential increase of correct answers. Memorization dynamics for some participants are given in Figure 10.

Individual memorization curves were also calculated for healthy children 6.7-7.4 years old (see Figure 8). The results are given in Table 4 and shows that our model provided an excellent fit in 14 of 15 children. $R^{2}$ exceeded .8 in all 14 subjects. One child memorized stepwise: He memorized $50 \%$ of images during the first trial and $100 \%$ during the remaining 5 trials. Memorization dynamics for some children are given in Figure 11. Taken together, these results clearly show that our model can be applied to both individual and group data.

(A)

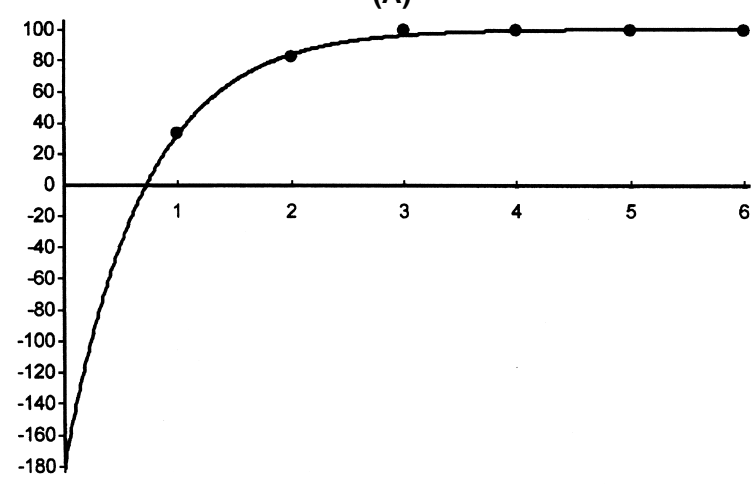

(B)

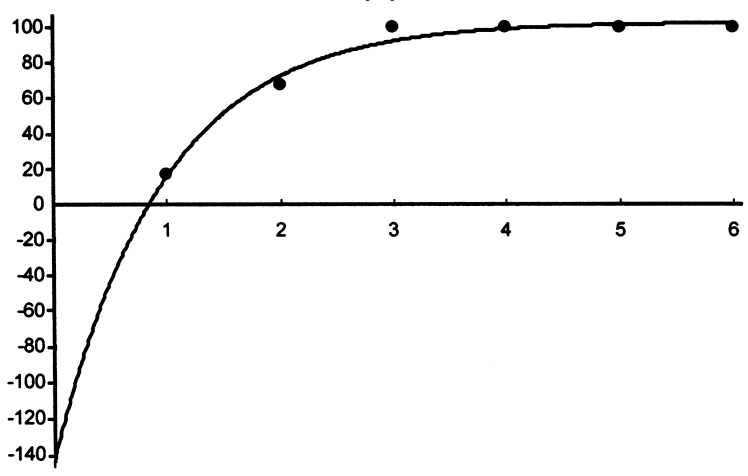

Dynamics of Memorization of Pictures and TwoDigit Numbers at Visual Presentation

For the purpose of developing a memory test that can be used in clinical applications, Stepanov developed a computer program for testing memorization of visual images and two-digit numbers shown on a computer screen ${ }^{1}$. Individual memorization of gymnastic pictures was studied in 18 randomly sampled healthy university students (age 20-25). The results are given in Table 5. The model provided an excellent fit in 11 of 18 subjects. $R^{2}$ exceeded .8 in 7 out of 11 subjects. For the remaining 4 subjects $R^{2}$ varied from .792 to .305 . We believe the lack of fit for these subjects was the result of a failure to concentrate on the task. Two examples of high $R^{2}$ are shown in Figure 12 .

Memorization dynamics that did not fit our model fall into several categories. One student memorized from $80 \%$ to $85 \%$ of the material throughout training, so that performance was very high from the beginning (Figure

(C)

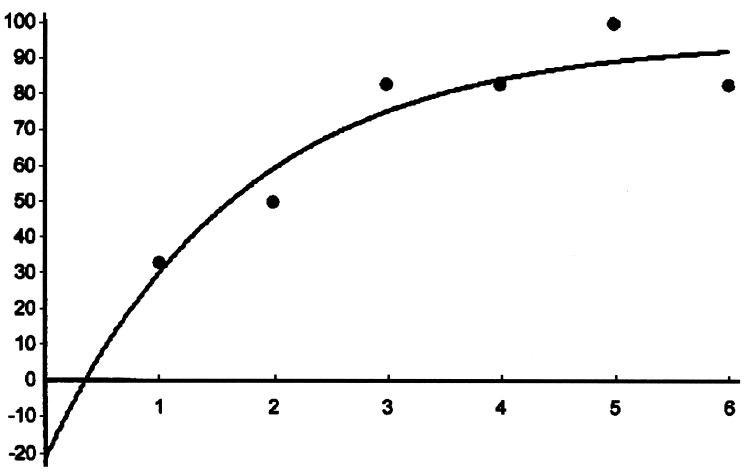

(D)

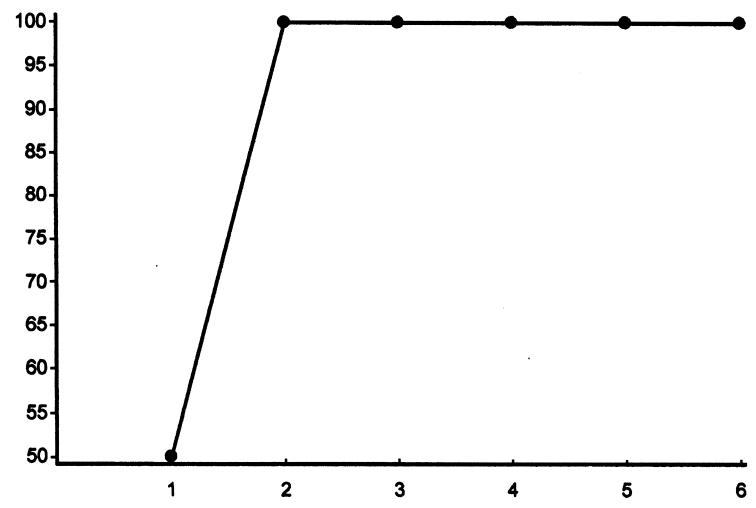

Figure 11. Individual memorization dynamics in healthy children in the age between 6.7 and 7.4 years old for pairs of different images. $A-$ Child 13; $\mathrm{B} 2=1.41 ; \mathrm{B} 3=-178.3 ; \mathrm{B} 4=101.0 ; R^{2}=.9965 . B-$ Child $15 ; \mathrm{B} 2=1.04 ; \mathrm{B} 3=-142.9 ; \mathrm{B} 4=103.0 ; R^{2}=.9825 . C$ - Child 2; B2 $=0.58 ; \mathrm{B} 3=-21.4 ; \mathrm{B} 4=96.2 ; R^{2}=.8892 . D-$ Child 1. Black dots $=$ experimental data; curves = result of calculations. Abscissa $=$ the number of trial; ordinate $=$ percentage of correct responses.

\footnotetext{
1 The last version (in English and in German) of the program MDT (Memorization Dynamics Test) uses picture sets "Gymnasts," "Playing cards," and memorization of 12 two-digit numbers, and is supplied with comprehensive help file. It can be downloaded free from the WEB SITE address www.iemrams.spb.ru/english/pharmacol/stepanov/stepanov.pl
} 
Table 4

Memorization of Different Images by Every Child from the Group of Healthy Children Between 6.7 and 7.4 Years Old

\begin{tabular}{|c|c|c|c|c|c|c|}
\hline \multirow{2}{*}{ Subject } & \multicolumn{3}{|c|}{ Coefficients } & \multicolumn{2}{|c|}{ Correct answers, \% } & \multirow[t]{2}{*}{$R^{2}$} \\
\hline & B2 & B3 & B4 & Minimal case & Maximal case & \\
\hline 1 & $>3.0$ & - & - & 50 & 100 & - \\
\hline 2 & $0.58 \pm 0.047$ & $-21.4 \pm 16.0$ & $96.2 \pm 5.4$ & 33 & 100 & .8892 \\
\hline 3 & $0.27 \pm 0.028$ & $-1.7 \pm 12.5$ & $122.9 \pm 9.9$ & 33 & 100 & .8469 \\
\hline 4 & $0.45 \pm 0.025$ & $-18.4 \pm 10.2$ & $113.8 \pm 4.6$ & 33 & 100 & .95 \\
\hline 5 & $1.41 \pm 0.014$ & $-178.3 \pm 8.2$ & $101.0 \pm 0.9$ & 33 & 100 & .9965 \\
\hline 6 & $0.44+0.020$ & $-39.7 \pm 9.7$ & $115.9 \pm 4.5$ & 17 & 100 & .966 \\
\hline 7 & $0.07 \pm 0.005$ & $0.0 \pm 5.6$ & $302.3 \pm 19.0$ & 17 & 100 & .9327 \\
\hline 8 & $0.31 \pm 0.018$ & $-10.4 \pm 7.0$ & $101.7 \pm 4.8$ & 17 & 83 & .9463 \\
\hline 9 & $0.23 \pm 0.021$ & $10.9 \pm 7.6$ & $112.8 \pm 7.2$ & 33 & 83 & .8848 \\
\hline 10 & $0.63 \pm 0.061$ & $2.4 \pm 17.0$ & $101.8 \pm 5.2$ & 50 & 100 & .8451 \\
\hline 11 & $0.46 \pm 0.019$ & $-4.1 \pm 5.7$ & $92.3 \pm 2.5$ & 33 & 83 & .9706 \\
\hline 12 & $0.29 \pm 0.027$ & $17.4 \pm 10.0$ & $124.1 \pm 7.3$ & 50 & 100 & .8772 \\
\hline 13 & $1.41 \pm 0.014$ & $-178.3 \pm 8.2$ & $101.0 \pm 0.9$ & 33 & 100 & .9965 \\
\hline 14 & $0.59 \pm 0.023$ & $-21.4 \pm 8.1$ & $102.6 \pm 2.7$ & 33 & 100 & .9723 \\
\hline 15 & $1.04 \pm 0.027$ & $-142.9 \pm 15.3$ & $103.0 \pm 2.6$ & 17 & 100 & .9825 \\
\hline
\end{tabular}
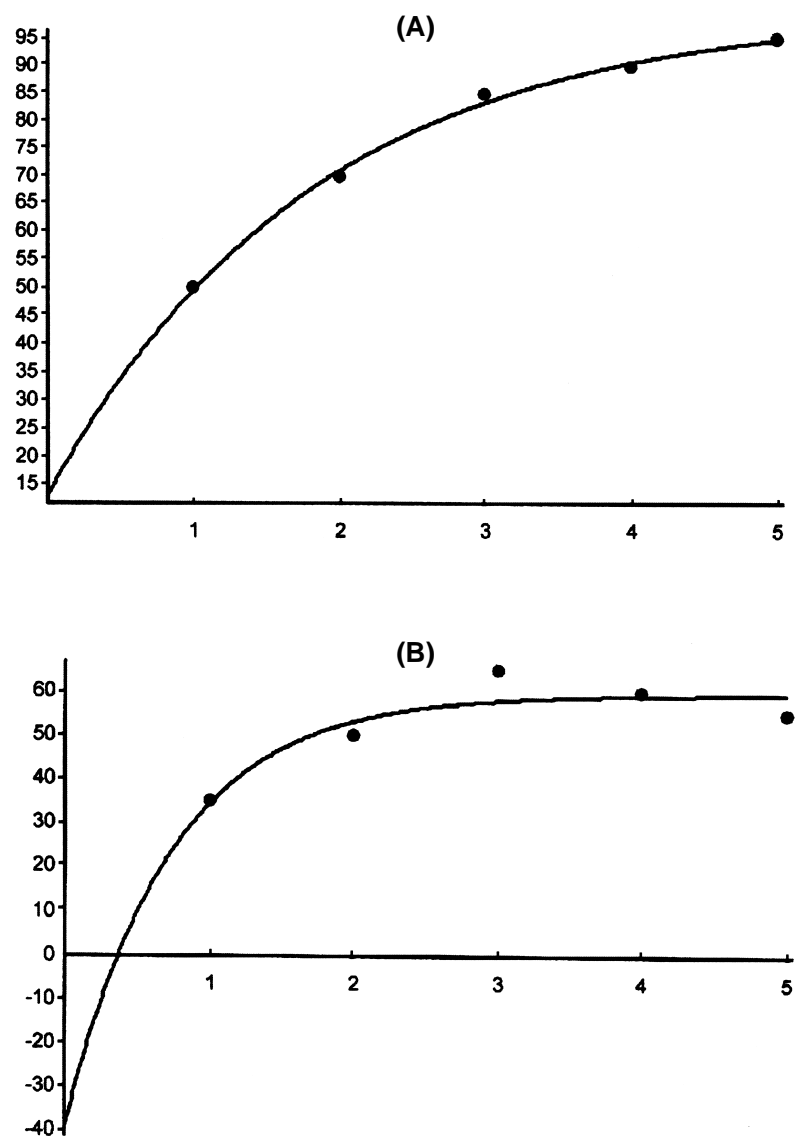

Figure 12. Memorization of gymnastic pictures in healthy university students fitted with the exponential mathematical model.

$A-$ Student $7 ; B-$ Student 14. Black dots = experimental data; curves $=$ result of calculations. Abscissa $=$ the number of trial; ordinate $=$ percentage of correct responses.
13.A). This might represent a "ceiling" effect in which the test was too easy. Two other students showed a rather low percentage of correct answers on the first trial but from the second trial increased their performance to a high level (Figure 13.B). Perhaps, these students were not concentrating on the test at the beginning of training, but quickly became attentive as the experiment progressed. In two other students, the value of correct responses decreased as testing continued (Figure 13.C). In one student the dynamics increased monotonically, but nearly as a straight line. We suppose that these five students were not motivated to concentrate on the memory task, which in turn did not lead to the expected exponential increase in correct answers. As a final example, one student showed an initial increase followed by decrease in the percent of correct answers (Figure 13.D). The reason for such a dome-shaped curve is unclear. Perhaps it was the result of fatigue or it could be a real dysfunction of working memory.

We also calculated memorization coefficients for these 18 subjects united together as a group. The regression analyses supported our model (Figure 14). Both tests for goodness of fit showed that the mathematical model fitted well the memorization dynamics. The square of correlative relation was $R^{2}=99$. The exponential memorization curve is peculiar to most individuals as represented in group or individual data.

In pilot experiments with normal older people of 60-67 years old, an exponential memorization curve was also found. As in the case with younger subjects, in older people, the task involved memorizing playing cards and was easier to perform (Figure 15.A) in comparison with memorization of numbers (Figure 15.B). Moreover, normal older people were able to memorize practically all the test images or 
Table 5

Memorization of Gymnastic Pictures by University Students

\begin{tabular}{|c|c|c|c|c|c|c|}
\hline \multirow{2}{*}{ Subject } & \multicolumn{3}{|c|}{ Coefficients } & \multicolumn{2}{|c|}{ Correct answers, \% } & \multirow[t]{2}{*}{$R^{2}$} \\
\hline & B2 & B3 & B4 & Minimal case & Maximal case & \\
\hline 1 & $0.65 \pm 0.025$ & $30.5 \pm 4.6$ & $103.3 \pm 1.6$ & 65 & 100 & .981 \\
\hline 2 & $0.51 \pm 0.051$ & $16.4 \pm 6.1$ & $60.1 \pm 2.8$ & 35 & 55 & .8885 \\
\hline 3 & $0.33 \pm 0.050$ & $45.9 \pm 8.7$ & $104.0 \pm 6.4$ & 65 & 90 & .7918 \\
\hline 4 & $0.29 \pm 0.115$ & $45.1 \pm 9.7$ & $72.4 \pm 8.3$ & 50 & 70 & .3567 \\
\hline 5 & $2.27 \pm 0.563$ & $247.8 \pm 199.1$ & $33.1 \pm 9.5$ & 10 & 55 & .3049 \\
\hline 6 & $0.39 \pm 0.024$ & $-6.8 \pm 6.6$ & $88.2 \pm 4.0$ & 25 & 75 & .9576 \\
\hline 7 & $0.54 \pm 0.008$ & $13.2 \pm 2.0$ & $100.8 \pm 0.8$ & 50 & 95 & .997 \\
\hline 8 & $<0.0$ & - & - & 35 & 65 & - \\
\hline 9 & $0.85 \pm 0.064$ & $-25.0 \pm 16.4$ & $86.4 \pm 4.0$ & 40 & 85 & .9227 \\
\hline 10 & $<0.0$ & - & - & 40 & 85 & - \\
\hline 11 & $>3.0$ & - & - & 20 & 85 & - \\
\hline 12 & $<0.0$ & - & - & 55 & 75 & - \\
\hline 13 & $<0.0$ & - & - & 80 & 85 & - \\
\hline 14 & $1.37 \pm 0.127$ & $-39.2 \pm 24.2$ & $59.7 \pm 3.0$ & 35 & 65 & .8477 \\
\hline 15 & $1.49 \pm 0.264$ & $-27.6 \pm 42.7$ & $59.0 \pm 4.7$ & 40 & 70 & .5849 \\
\hline 16 & $0.29 \pm 0.025$ & $65.6 \pm 3.1$ & $104.9 \pm 2.6$ & 75 & 95 & .9186 \\
\hline 17 & $<0.0$ & - & - & 60 & 85 & - \\
\hline 18 & $>3.0$ & - & - & 50 & 85 & - \\
\hline
\end{tabular}

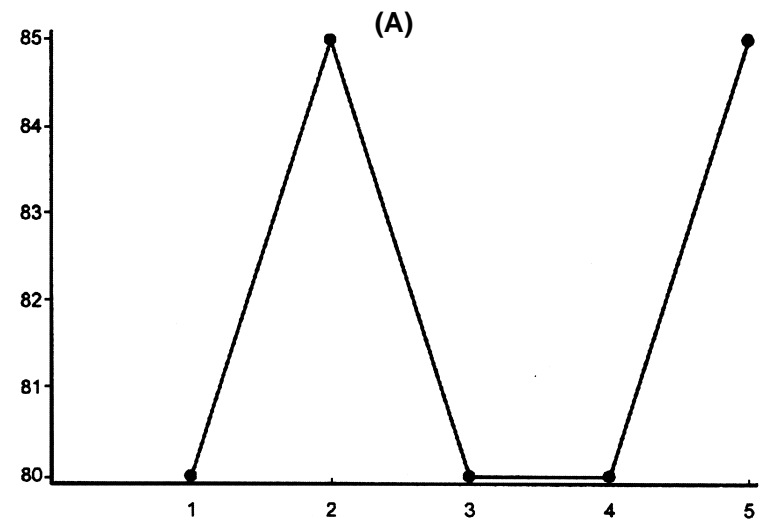

(B)

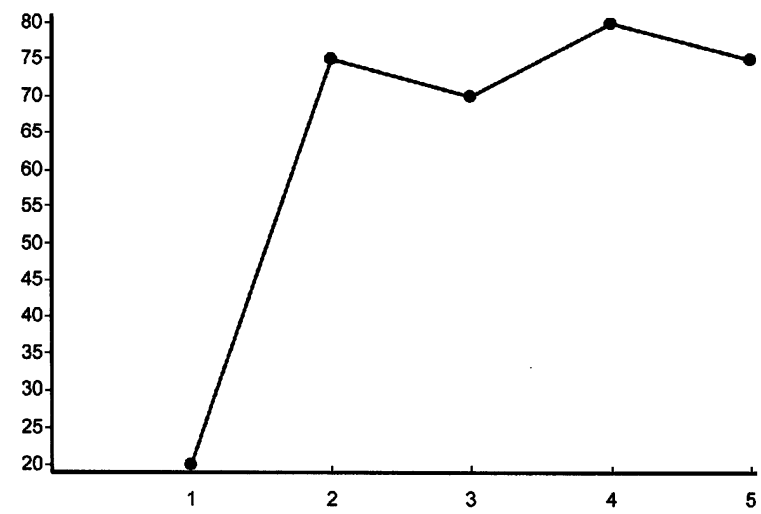

(C)

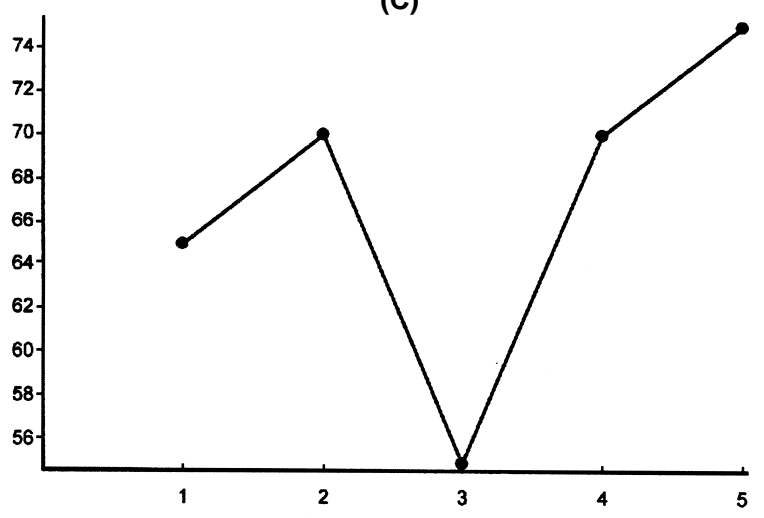

(D)

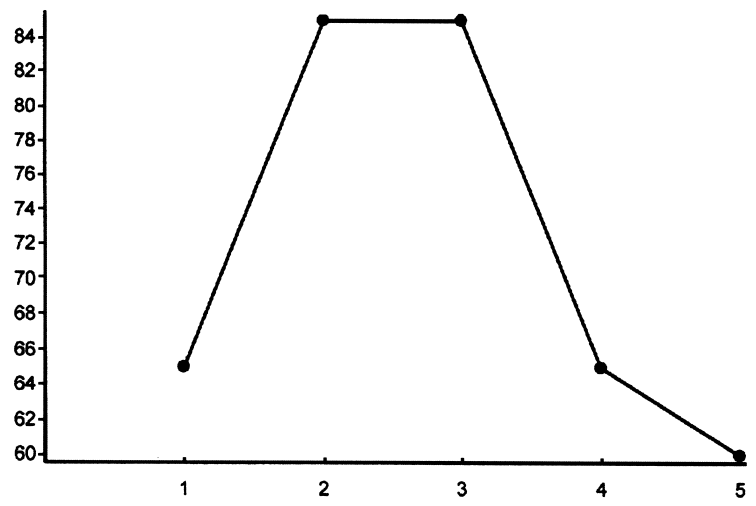

Figure 13. Memorization of gymnastic pictures in healthy university students not fitted with the exponential mathematical model. $A-$ Student $13 ; B-$ Student $11 ; C-$ Student $12 ; D-$ Student 17. Black dots = experimental data; curves = result of calculations. Abscissa $=$ the number of trial; ordinate $=$ percentage of correct responses. 


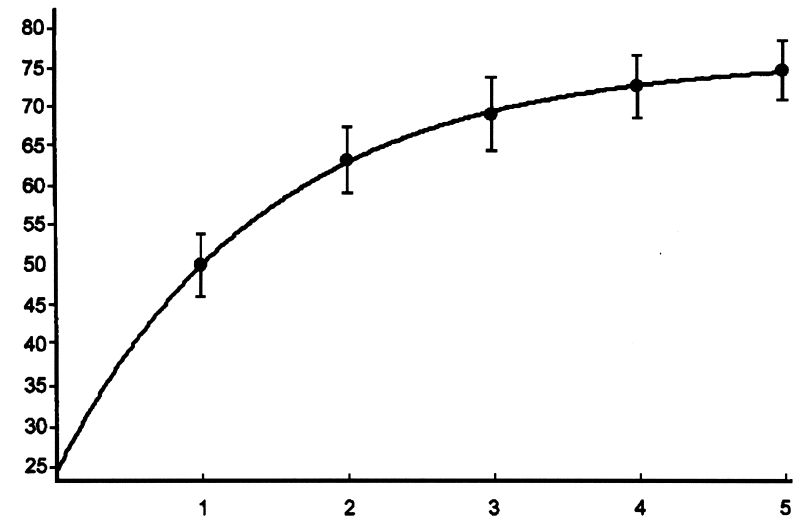

Figure 14. Memorization of gymnastic pictures by the whole group of these healthy university students.

$\mathrm{B} 2=0.6 \pm 0.02 ; \mathrm{B} 3=24.6 \pm 6.9 ; \mathrm{B} 4=76.3 \pm 2.2$. Filled dots with vertical lines are means with S.E.M. Solid curve is fitting with the mathematical model. Abscissa $=$ the number of trial; ordinate $=$ percentage of correct responses.
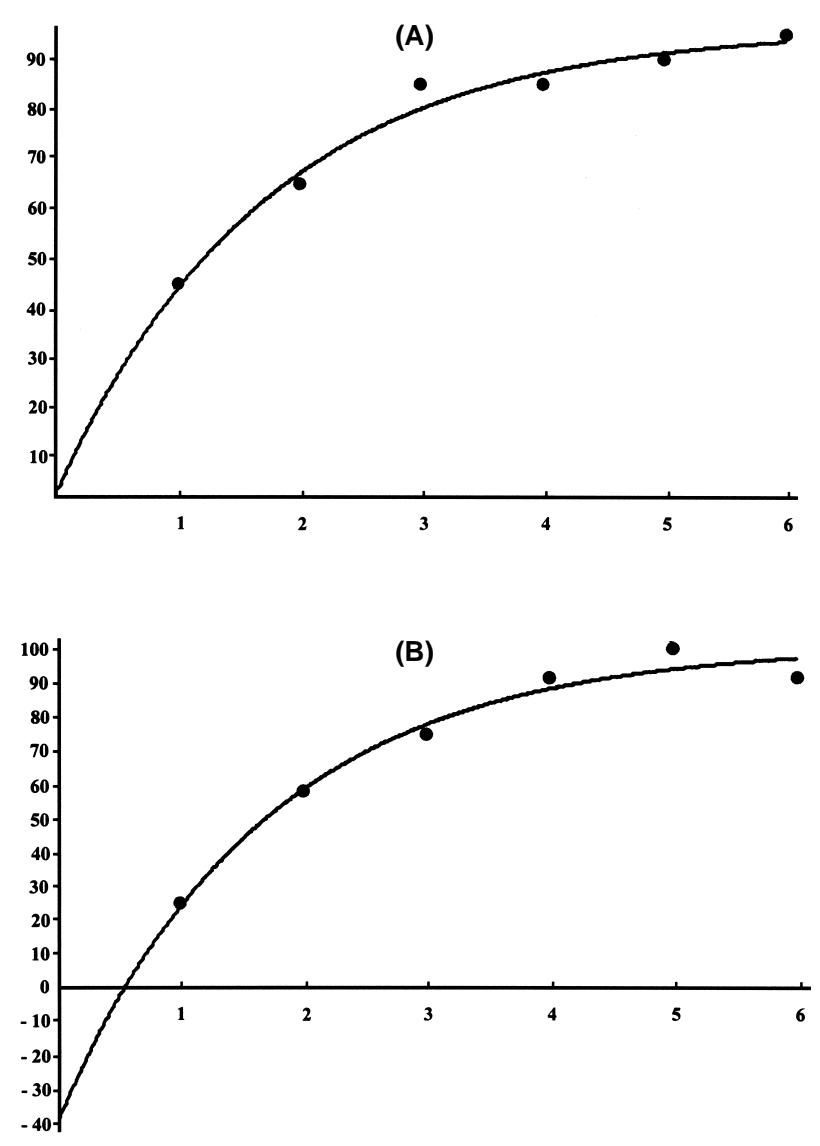

Figure 15. Dynamics of memorization in healthy elder person (Subject O. E., 67 years old).

$A-10$ playing cards; $\mathrm{B} 2=0.58 ; \mathrm{B} 3=3.7 ; \mathrm{B} 4=96.6 ; R^{2}=.9785$.

$B-12$ two-digit numbers. $\mathrm{B} 2=0.25$; $\mathrm{B} 3=-8.1$; B4 = 108.9;

$R^{2}=0.9835$. Black dots $=$ experimental data; Solid curve is fitting with the mathematical model. Abscissa = the number of trial; ordinate $=$ percentage of correct responses. numbers. We suppose that principles of memory formation, manifesting in exponential shape of learning/memorization curve, remain the same in older people as in younger people. Hence, the lack of exponential memorization curve can turn out to be the earliest sign of a genuine working memory dysfunction in elders.

\section{Discussion}

Our results show that for some simple learning paradigms, in both animals and humans, the learning curve is of an exponential type. It is important that the model contains a coefficient which shows a $\mathrm{Y}$ value at $\mathrm{X}=0$. This coefficient assesses the initial value of pretrial associative strength, which may vary from negative to positive. Our model can be applied to group or individual data.

It is necessary to emphasize that the exponential learning dynamics is attributable to thoroughly designed learning or memorization tests where most of the interfering factors are eliminated. For our model to be effective, the subject must be motivated to complete the task.

We are certainly aware that there exist other forms of learning curves, for example, step-like, and S-shapes (Fedotova, 2000; Gallistel et al., 2004; Nikolskaya \& Khonicheva, 1999). We also noted such shapes in our data. This may be the result of other brain mechanisms being activated during testing or related to the type of task. From our point of view, all S-shape and step-like (the output of the step-like model is equal to zero during some initial trials and later takes the value of $100 \%$ ) learning mathematical models, for example, are not able to assess the initial level of associative strength (readiness for next learning trial), because of the lack of a coefficient analogous to our B3.

As the most important practical application of the mathematical model is its use for individual testing of humans, we pay special attention to the cases that do not meet the mathematical model or, in other words, the exponential dynamics for an individual curve is absent. We suggest that the reasons for some aspects of our data not conforming to the model may be as follows: (a) easiness or difficulty of the test, (b) low concentration or lack of attention to the task, (c) low level of drive and motivation, and (d) a genuine working memory dysfunction.

Firstly, if memorization of 10 test pictures or two-digit numbers is easy for a subject, the number of correct responses is situated in the range of $80-100 \%$ from the first trial. It means that a subject reaches at once his/her asymptotic (plateau) level, where there cannot be further improvement. So, some oscillations of the values of correct responses can be seen instead of the exponential learning curve. To avoid this problem, it is necessary to use a different number of test stimulus (pictures or numbers), for example, from 10 up to 15-16. Moreover, picture sets with far, middle, and close discrimination distance between the test images 
and their distracters must be developed. Nowadays, we use for this purpose a standardized set of 260 pictures developed by Snodgrass and Vanderwart (1980) as well as produce our own set of pictures. In general, the set of stimulus with valid level of difficulty must be selected individually for every subject under testing. The test must allow personal adjustment for every healthy individual so that everyone with normal brain functioning can receive an exponential curve for memorization dynamics.

Secondly, absence of the exponential learning curve can be the result of impaired attention and inability to concentrate on the task instead of memory impairment. To elucidate the role of impaired attention, we are going to add some tests for sustained attention and for assessment of the time for simple sensory-motor reaction in response to audio or visual stimulus.

Thirdly, close attention must be paid to the motivation of every subject. Our experience shows that the exponential learning curve needs very high concentration of subject's attention on the task. Healthy volunteers, especially among young people, frequently are not very interested in the exact results of their testing and do not try to do their best. We suppose that additional pretesting preparation for facilitation of increasing of attention should be included into our computerized memory test.

Assuming that the first three reasons for absence of the exponential memorization curve can be excluded, the absence of an exponential learning curve can become the earliest sign of a genuine working memory dysfunction. Generally speaking, all diseases that lead to initial memory dysfunction due to different reasons will manifest the absence of normal memorization dynamics. In particular, deviation from a predicted learning curve can be the first preclinical sign for the future appearance of, for example, Alzheimer's in older people. Our experiments with beta-amyloid-treated Wistar rats support this hypothesis (Sapronov \& Stepanov, 2004). Our model can also be used to test the efficacy of various drugs to improve memory.

\section{References}

Albert, M.S. (1996). Cognitive and neurobiological markers of early Alzheimer disease. Proceedings of National Academy of Sciences USA, 93, 13547-13551.

Atkinson, R.C., Bower, G.H., \& Crothers, E.J. (1965). An introduction to mathematical learning theory. New YorkLondon-Sydney: Wiley.

Balaban, P.M., \& Stepanov, I.I. (1996). Innate and acquired behavior of mollusks. In C.I. Abramson, Z.P. Shuranova, \& Y.M. Burmistrov (Eds.), Russian contributions to invertebrate behavior (pp. 77-109). Westport, CT: Praeger and Greenwood Publishing Group.

Delis, D.C., Kramer, J.H., Kaplan, E., \& Ober, B.A. (1987). California Verbal Learning Test. San Antonio, TX: The Psychological Corporation.
Draper, N.R., \& Smith, H. (1981). Applied regression analysis. New York: Wiley.

Fedotova, Yu. O. (2000). The effects of the hormones of peripheral endocrine glands on the processes of behavior, learning, and memory. Neuroscience and Behavioral Physiology, 30, 75-80.

Folstein, M.F., Folstein, S E., \& McHugh, P.R. (1975). "MiniMental State". A practical method for grading the cognitive state of patients for the clinician. Journal of Psychiatric Researches, 12, 189-198.

Gallistel, C.R., Fairhurst, S., \& Balsam, P. (2004). The learning curve: Implications of a quantitative analysis. Proceedings of National Academy of Sciences USA, 101, 13124-13131.

Goncharov, O.V., Usenko, Yu. I., \& Stepanov, I.I. (2002). Meditsinskaya reabilitatsiya s ispolsovaniem nootropov i acupuncturi [Medical rehabilitation with use of nootropics and acupuncture]. In O.F. Erishev, T.G. Rybakova, \& P.D. Shabanov (Eds.), Alcoholic dependence (pp. 126-146). St.-Petersburg: ELBY-SPb.

Grodins, F.S. (1963). Control theory and biological systems. New York, London: Columbia University Press.

Grober, E., \& Buschke, H. (1987). Genuine memory deficits in dementia. Developmental Neuropsychoogy, 3, 13-36.

Gulliksen, H. (1934). A rational equation of the learning curve based on Thorndike's law of effect. Journal of General Psychology, 11, 395-434.

Himmelblau, D.M. (1970). Process analysis by statistical methods. New York: Wiley.

Hull, C.L. (1943). Principles of behavior. New York: Appleton Century Crofts.

Kendall, M.G., \& Stuart, A. (1975). The advanced theory of statistics. 3. London: Charles Griffin.

Nikolskaya, K.A., \& Khonicheva, N.M. (1999). Osobennosti obucheniya krys v usloviyakh svobodnogo vybora [Peculiarities of rat learning under free-choice conditions]. Zhurnal vistshei nervnoi deyatelnosti, 49, 436-445.

Lokhov, M.I., \& Stepanov, I.I. (1987). Metod issledovaniya assotsiativnoy pamyaty u detei [The method of estimation of children's associative memory]. Patent No. 1292733 (USSR). Byulleten' izobretenii, 8 .

Lokhov, M.I., \& Stepanov, I.I. (1988). Metod opredeleniya funktsional'nogo sostoyaniya tsentral'noi nervnoi sistemi u tcheloveka [The method of estimation of a man's CNS functional state]. Patent No. 1377037 (USSR). Byulleten' izobretenii, 8.

Lokhov, M.I., Stepanov, I.I., \& Vartanian G.A. (1990). Evolutsionnie aspekti dinamiki virabotki prostikh uslovnikh refleksov [Evolutionary aspects of simple conditioned reflexes elaboration dynamics]. Zhurnal Evolutsionnoy Biokhimii i Phiziologii, 26, 213-219.

Lokhov, M.I., Stepanov, I.I., Edlina, T.A., \& Vartanian, G.A. (1993). Dinamika formirovaniya proizvol'noi pamyati u detei [The dynamics of voluntary memory formation in children]. Psikchologicheskiy Zurnal, 14, 56-65.

Luria, A.R. (1962). Vishye korkovye funktzii tcheloveka $i$ ikh narusheniya pri lokal'nikh povrezhdeniyakh mozga [The higher cortical functions in humans and their dysfunctions at local brain injury]. Moscow: Moscow State University Publishing House. 
Maurice, T., Lockhart, B.P., \& Privat, A. (1996). Amnesia induced in mice by centrally administered $\beta$-amyloid peptides involves cholinergic dysfunction. Brain Research, 706, 181-193.

Paxinos, G., \& Watson C. (1986). The rat brain in stereotaxic coordinates ( $2^{\text {nd }}$ ed.). San Diego, CA: Academic Press.

Robbins, T., James, M., Owen, A., Sahakian, B., McInnes, L., \& Rabbitt, P. (1994). Cambridge Neuropsychological Test Automated Battery (CANTAB): A factor analytic study of a large sample of normal elderly volunteers. Dementia, 5, 266-281.

Sapronov, N.S., \& Stepanov, I.I. (1996). Impairment of fine shortterm memory mechanisms with some neurotropic drugs. European Neuropsychopharmacology, 6, Suppl. 3, 186.

Sapronov, N.S., \& Stepanov, I.I. (2004). Non-lineal rats are resistant to memory disruption with beta-amyloid. Psychiatrie, 8 , Suppl. 4, 43-44.

Shabanov, P.D., Stepanov, I.I., Usenko, Yu. I., \& Goncharov, O.V. (2000). Rol' akupunkturi v reabilititsionnom lechenii alcogolokov [The role of acupuncture in rehabilitation healing of alcoholics]. Klinitcheskaya meditsina I patofiziologiya, 2, 38-43.

Snodgrass, J. G., \& Vanderwart M. (1980). A standardized set of 260 pictures: Norm for name agreement, image agreement, familiarity, and visual complexity. Journal of Experimental Psychology: Human Learning and Memory, 6, 174-215.

Stepanov, I.I. (1983). Priblizhennii metod othsenivaniya parametrov krivoi obutcheniya [An approximate method of estimation of the learning curve parameters]. Physiologiya Tcheloveka, 9, 686-689.
Stepanov, I.I., \& Lokhov, M.I. (1986). Dinamika virabotki uslovnikh refleksov I differentsirivki u nazemnoi ulitki, Helix pomatia [Dynamics of elaboration of conditioned reflex and stimuli discrimination in the land snail, Helix pomatia]. Zhurnal vistshei nervnoi deyatelnosti, 36, 698-706.

Stepanov, I.I., Lokhov, M.I., Satarov, A.S., Kuntsevich, S.V., \& Vartanyan, G.A. (1988). Humoral link in the mechanism of formation of the food refusal conditioned response in the snail. Neuroscience and Behavioral Physiology, 18, 257264.

Swainson, R., Hodges, J., Galton, C., Semple, J., Michael, A., Dunn, B., Iddon, J.L., Robbins, T.W., \& Sahakian, R.J. (2001). Early detection and differential diagnosis of Alzheimer's disease and depression with neuropsychological tasks. Dementia and Geriatric Cognitive Disorders, 12, 265-280.

Towill, D.R. (1976). Transfer functions and learning curves. Ergonomics, 19, 623-638.

Wechsler, D. (1987). Wechsler Memory Scale-Revised. San Antonio, TX: Psychological Corporation.

Wixted, J.T. (1997). Genuine power curves in forgetting: A quantitative analysis of individual subject forgetting functions. Memory \& Cognition, 25, 731-739.

Received May 16, 2005 Revision received July 20, 2005 Accepted July 25, 2005 